\title{
Numerical Simulation of Vaporous Hydrogen Peroxide Diffusion under Different Speed
}

\author{
Ting Liang ${ }^{1, \mathrm{a}}$, Kan Zhou ${ }^{2, \mathrm{~b}, *}$, Hailing $\mathrm{Xi}^{2, \mathrm{c}}$, and $\mathrm{Jin} \mathrm{Gu}^{1, \mathrm{~d}}$ \\ ${ }^{1}$ Institute of Chemical Defense, Yangfang, Beijing, China \\ ${ }^{2}$ Chemical prevention research institute, Yangfang, Beijing, China \\ a liangting2001@sina.com, b517525860@qq.com, c fhxihl@163.com, d gj8410@126.com \\ *corresponding author
}

Keywords: Numerical Simulation, Vaporous Hydrogen Peroxide, Diffusion, Different Speed

\begin{abstract}
This paper adopts the computation fluid dynamics(CFD) to research the diffusion law of vaporous hydrogen peroxide(VHP) under different inlet velocities include $0.1 \mathrm{~m} / \mathrm{s}, 0.2 \mathrm{~m} / \mathrm{s}$ and $0.4 \mathrm{~m} / \mathrm{s}$. The results show that when the inlet velocity is $0.4 \mathrm{~m} / \mathrm{s}$, the concentrations of VHP in different locations can meet the decontamination demand but the consumption of hydrogen peroxide solution is large. When the inlet velocity is $0.1 \mathrm{~m} / \mathrm{s}$, at 1200 seconds the lowest concentration is only $6 \mathrm{ppm}$, which cannot meet the demand of the decontamination. When the inlet velocity is $0.2 \mathrm{~m} / \mathrm{s}$, the vaporous hydrogen peroxide is evenly distributed in space and the concentrations can meet the decontamination demand, and the hydrogen peroxide solution also consumes less.
\end{abstract}

\section{Introduction}

Space disinfection has a wide range of applications in production and daily life, such as: clean room of pharmaceutical production enterprises, not only aerosols in the air, but also microbe number are controlled, space disinfection is necessary[1]. Space of traditional sterilization method with ultraviolet light irradiation, chemical drugs (such as $40 \%$ formaldehyde, epoxy ethane, lactic acid) gas sterilization, the most commonly used by formaldehyde method[2]. Better disinfection effect of formaldehyde gas, but the long-term use will because of formaldehyde polymerization and precipitation of white powder attached to the surface of the walls and equipment, so that the metal rusts, and sterilizing time dependence on relative humidity (65\%), harmful to the human body, strong stimulation, need a long air exchange process to production the shortcomings of. Almost all pharmaceutical companies are looking for a stable, space disinfection products can replace formaldehyde[3]. In addition, disinfection of space is also suitable for biological safety laboratory, experimental animal center, pharmaceutical factory GMP workshop, infectious disease wards need regular disinfection and sterilization in place.

Vaporous hydrogen peroxide (VHP) can oxidize many microorganisms including bacteria spores, at the same time; it almost no harm to public health[4]. Because of its high security, characteristic of no residue, colorless, tasteless and non-toxic, hydrogen peroxide disinfectant is widely applied in production[5]. At present the research on space hydrogen peroxide vapor sterilization mainly concentrated on the research on the disinfection effect of microorganism, not mathematics model is established for numerical simulation of space inside the vapor diffusion, this paper adopts the computation fluid dynamics(CFD) to research the diffusion law of vaporous hydrogen peroxide(VHP) under different inlet velocities in order to provide suggestions to space disinfection.

\section{Mathematical Model}

In this paper, the simulation of disinfection space is hospital operation room. Space size is $7.5 \times 5.7 \times 3 \mathrm{~m}$. Vaporous Hydrogen peroxide through the air-conditioning pipe mixed air enter the 
disinfection space, central air-conditioning fresh air blower system adopts centralized; the air outlet located at the top of the room, the size is $2.5 \times 2 \mathrm{~m}$, area is $5 \mathrm{~m}^{2}$. Return air system is set up independently, is located on the left and right side of the room, the size is $3 \times 0.4 \mathrm{~m}$, the height is $0.2 \mathrm{~m}$ and the area is $2.4 \mathrm{~m}^{2}$.

\subsection{The Control Equation}

In the calculation of internal flow field, the influence of temperature and humidity on the gas flow field and the rise of buoyancy airflow were not considered. Air velocity in the flow field magnitude was small (less than $1 \mathrm{~m} / \mathrm{s}$ ), internal air can be handled as incompressible flow. This paper uses the CFD software Fluent to simulate.The $k-\varepsilon$ mode was chosed to describe the diffusion of VHP.The improved SIMPLEC algorithm can meet the requirements.

\subsection{The Boundary Condition}

The average wind speed in the operation table area is $0.25 \sim 0.3 \mathrm{~m} / \mathrm{s}$, so the outlet wind speed is set as $0.4 \mathrm{~m} / \mathrm{s}$, the export wind volume is $2 \mathrm{~m}^{3} / \mathrm{s}$, the concentration of hydrogen peroxide vapor in outlet airflow was set as $825 \mathrm{ppm}$, which can meet the requirement of disinfection and sterilization. The outlet pressure gauge pressure was set as $-15 \mathrm{~Pa}$.

\section{Calculation Results and Analysis}

The gas inlet of the operation room is on the top and the area is $5 \mathrm{~m}^{2}$, the inlet $\mathrm{t}$ velocity was set to $0.4 \mathrm{~m} / \mathrm{s}$, the volume was $2 \mathrm{~m}^{3} / \mathrm{s}$. The gas outlet is located at the left and right sides of the room, the area is $2.4 \mathrm{~m}^{2}$, After VHP injection for 240 seconds and 900 seconds, the concentration distributions are shown in Figure 1(a) and Figure 1(b). The lowest concentration of vaporous hydrogen peroxide at the speed of $0.4 \mathrm{~m} / \mathrm{s}$ is shown in Figure 1(c).

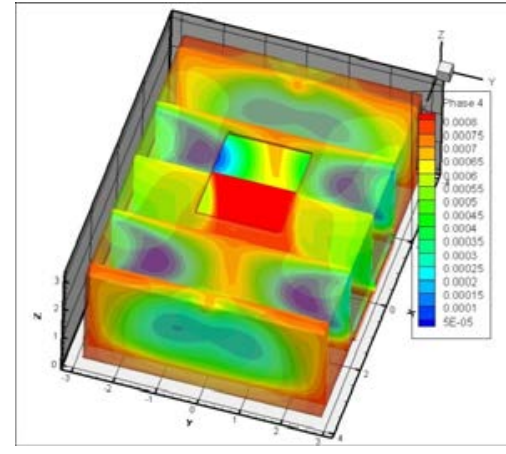

(a) 240 seconds

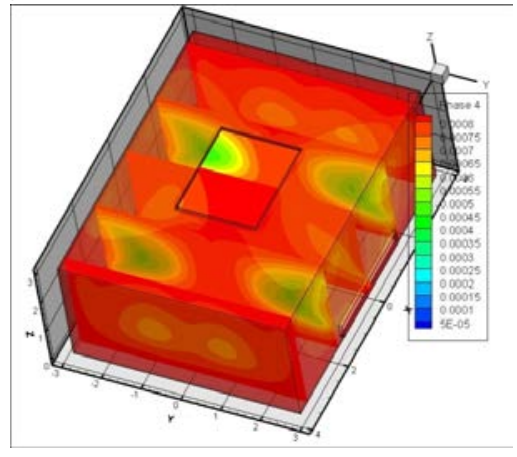

(b) 900 seconds

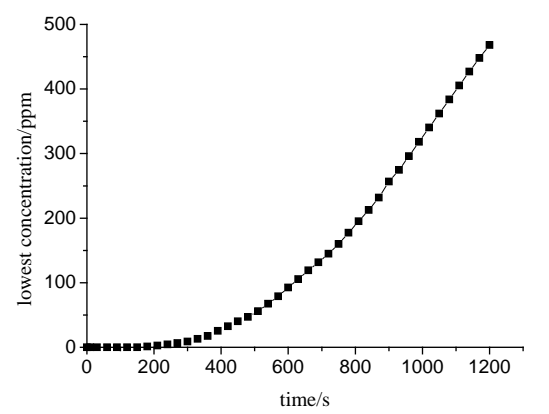

(c) lowest concentration of VHP

Figure 1 Concentration distribution of vaporous hydrogen peroxide at the speed of $0.4 \mathrm{~m} / \mathrm{s}$

From the lowest concentration curve: the lowest vapor hydrogen peroxide concentration versus time increase, the lowest concentration slowly increased in earlier stage, later increased faster. At 990 seconds, the minimum concentration of VHP exceeds 300ppm. At 1110 seconds, the lowest concentration exceeds 400ppm.At 1200 seconds, the lowest concentration reached 468ppm, the concentration satisfies the decontamination requirements. VHP concentration at all locations in the room reach saturation at $468 \mathrm{ppm}$, which can meet the requirements of decontamination without dead angle. The consumption of $30 \%$ hydrogen peroxide solution was $500 \mathrm{~g} / \mathrm{min}$.

When inlet velocity increase, more hydrogen peroxide solution is needed to saturate the VHP. The hydrogen peroxide solution consumption is large. In order to reduce the consumption of hydrogen peroxide solution, this paper will reduce the inlet velocity of vaporous hydrogen peroxide. The inlet velocity was set to $0.2 \mathrm{~m} / \mathrm{s}$, the volume was $1 \mathrm{~m}^{3} / \mathrm{s}$, the consumption of $30 \%$ hydrogen peroxide solution was $300 \mathrm{~g} / \mathrm{min}$ can maintain the vapor concentration at saturation concentration. After VHP injection for 480 seconds and 1200 seconds, the concentration distributions are shown in Figure 2(a) and Figure 2(b). The lowest concentration of vaporous hydrogen peroxide at the speed of $0.2 \mathrm{~m} / \mathrm{s}$ is shown in Figure 2(c). 


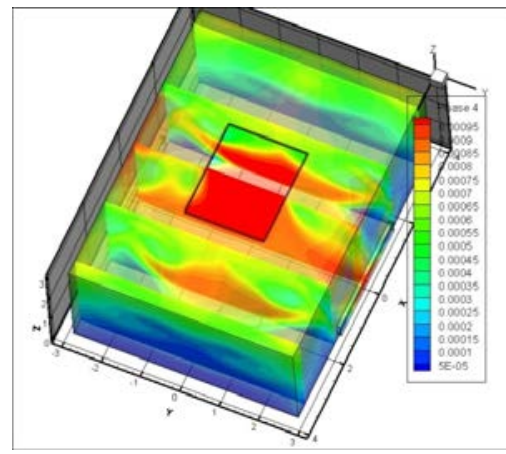

(a) 480 seconds

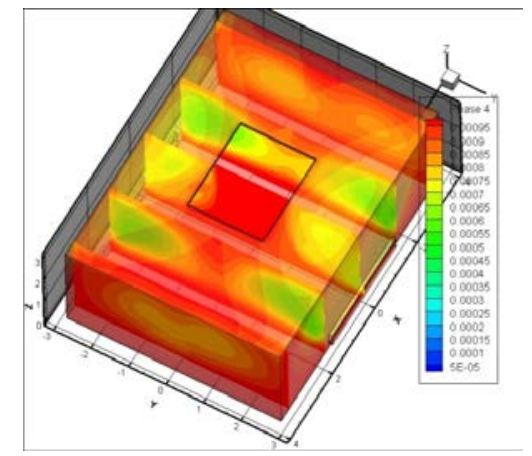

(b) 1200 seconds

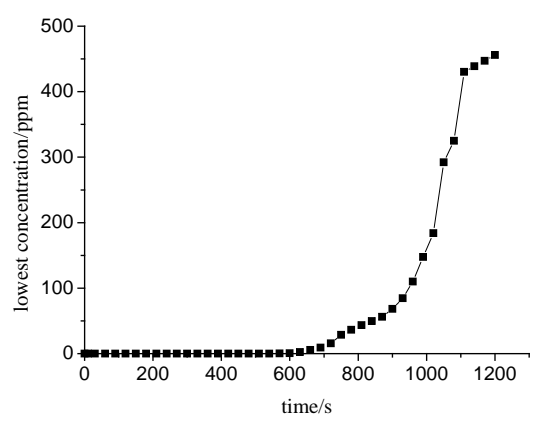

(c) lowest concentration of VHP

Figure 2 Concentration distribution of vaporous hydrogen peroxide at the speed of $0.2 \mathrm{~m} / \mathrm{s}$

The lowest concentrations of vaporous hydrogen peroxide are almost the same after 1200 seconds, when the inlet velocities are set at $0.2 \mathrm{~m} / \mathrm{s}$ and $0.4 \mathrm{~m} / \mathrm{s}$. And the larger the exit velocity, the better atomization quantity is needed to keep the saturated concentration of hydrogen peroxide vapor.

The paper further reduces the inlet velocity, the inlet velocity was set to $0.1 \mathrm{~m} / \mathrm{s}$, verify that the inlet velocity can make all the position in the space reach the effective concentration in 1200 seconds. Through the calculation when the outlet wind speed decreases to $0.1 \mathrm{~m} / \mathrm{s}$, the export capacity of $0.5 \mathrm{~m}^{3} / \mathrm{s}$. The consumption of $30 \%$ hydrogen peroxide solution was $200 \mathrm{~g} / \mathrm{min}$. After VHP injection for 360 seconds and 1200 seconds, the concentration distributions are shown in Figure 3(a) and Figure 3(b). The lowest concentration of vaporous hydrogen peroxide at the speed of $0.1 \mathrm{~m} / \mathrm{s}$ is shown in Figure 3(c).

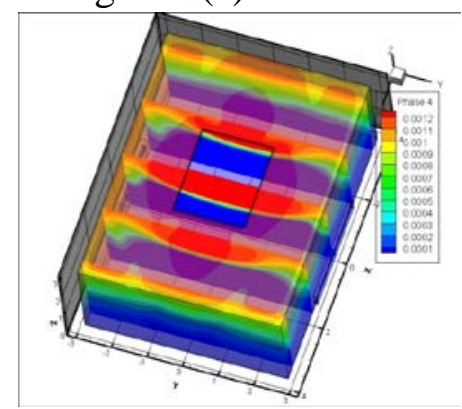

(a) 360 seconds

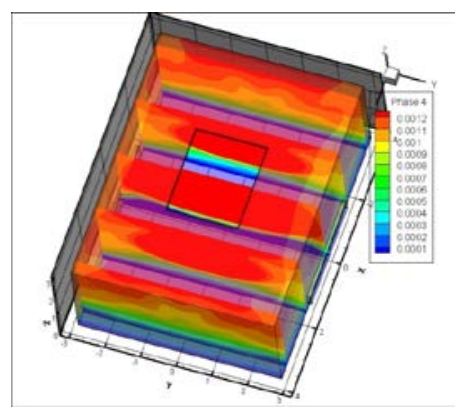

(b) 1200 seconds

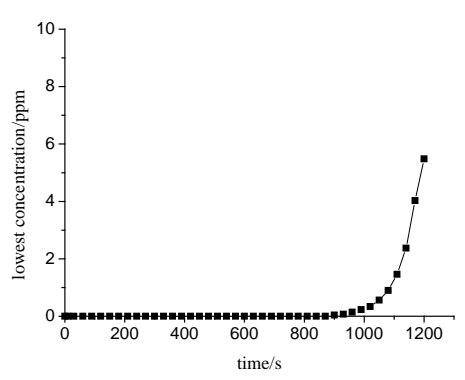

(c) lowest concentration of VHP

Figure 3 Concentration distribution of vaporous hydrogen peroxide at the speed of $0.1 \mathrm{~m} / \mathrm{s}$

When the inlet velocity decreases to $0.1 \mathrm{~m} / \mathrm{s}$, the lowest concentration of VHP in space barely changes during the first 1000 seconds. After 1000 seconds, the lowest concentration starts to rise, but the rise is slow, after 1200 seconds the lowest concentration of VHP is only 6ppm, which cannot meet the demand of the decontamination.

\section{Conclusion}

When the inlet velocity is $0.4 \mathrm{~m} / \mathrm{s}$, the concentrations of VHP in different locations are various, at the time of 1200 seconds the lowest concentration reach 468ppm, meet the decontamination demand, but the consumption of hydrogen peroxide solution is large. When the inlet velocity is $0.2 \mathrm{~m} / \mathrm{s}$, the concentrations of VHP in different locations are nearly. at the time of 1200 seconds the lowest concentration reach 455ppm, not only meet the demand of the decontamination but also reduce the consumption of hydrogen peroxide solution. When the inlet velocity is $0.1 \mathrm{~m} / \mathrm{s}$, at the time of 1200 seconds the lowest concentration is only 6ppm, cannot meet the demand of the decontamination.

\section{References}

[1] G. Wagner, L. Procell, D. Sorrick. B. Maclver, A. Turetsky, M. Schultz, M. Brickhouse, L.Schwarz, I. McVey, P. Wiget, J. Pfarr, D. Dutt, D. Strak, Large Scale Tests of Vaporous Hydrogen 
Peroxide (VHP) for Chemical and Biological Weapons Decontamination, Decon Downunder Conference, (2005).

[2] U.S. Environmental Protection Agency. Compilation of available data on building decontamination alternatives. Office of Research and Development. Washington, DC: National Homeland Security Research Center,(2005).

[3] M. Andrew. Vaporous Decontamination Methods: Potential Uses and Research Priorities for Chemical and Biological Contamination Control. Australian Defence Science and Technology Organisation, (2006).

[4] M.D. Brickhouse, A. Turestsky, I. McVey, Decontamination of CBW Agents by mVHP: Demonstration of the CBW decontamination of a building using mVHP. Edgewood Chemical Biological Center, (2005).

[5] J.V. Rogers, C.L.K. Sabourin, Y.W. Choi, W.R. Richter, D.C. Rudnicki, K.B. Riggs, M.L.Taylor and J.Chang ,Decontamination assessment of Bacillus anthracis, Bacillus subtilis, and Geobacillus stearothermophilus spores on indoor surfaces using a hydrogen peroxide gas generator, Journal of Applied Microbiology (2005). 99, 739. 